\title{
Computed Tomography Evaluation of Craniovertebral Junction in Asymptomatic Central Rural Indian Population
}

\author{
Prasheelkumar Premnarayan Gupta ${ }^{1}$ Atul Manohar Dhok ${ }^{2} \quad$ Salman T. Shaikh ${ }^{3} \quad$ Akshay Shrirang Patil ${ }^{4}$ \\ Deepak Gupta ${ }^{5}$ Nitin Nandkumar Jagdhane ${ }^{6}$
}

1Department of Neurosurgery, Mahatma Gandhi Institute of Medical Sciences, Sevagram, Maharashtra, India

${ }^{2}$ Department of Radiology, Mahatma Gandhi Institute of Medical Sciences, Sevagram, Maharashtra, India

${ }^{3}$ Division of Neurosurgery, Department of Surgical Oncology,

Tata Memorial Centre, Mumbai, Maharashtra, India

${ }^{4}$ Department of Neurosurgery, JN Medical College and AVBR

Hospital, Sawangi, Wardha, Maharashtra, India

${ }^{5}$ Department of Anaesthesia, JN Medical College and AVBR Hospital, Sawangi, Wardha, Maharashtra, India

${ }^{6}$ Department of Neurosurgery, Seven Hills Hospital, Mumbai,

Maharashtra, India

J Neurosci Rural Pract:2020;11:442-447

\begin{abstract}
Address for correspondence Atul Manohar Dhok, MD, Department of Radiology, Mahatma Gandhi Institute of Medical Sciences, Sevagram, Maharashtra, India (e-mail: dratuldhok@gmail.com).
\end{abstract}

\begin{abstract}
Keywords

- atlantodental interval

- basal angle

- Boogard's angle

- clivus length

- craniovertebral junction

- foramen magnum diameter

Objectives Craniovertebral junction (CVJ) is a unique, mobile and complicated component of our spine which necessitates specific study pertaining to its structure as well as pathologies. This study aims to report the normative data detailing the CV] anatomy among the rural population of Central India which would help us in understanding the joint dynamics.

Materials and Methods A retrospective observational study was undertaken in the Department of Neurosurgery and Radiology, Mahatma Gandhi Institute of Medical Sciences, Sewagram, Maharashtra, from December 2018 to May 2019. A total of 255 head injury patients with a normal CT brain cervical spine were included in this study. Anterior and posterior atlantodental interval (AADI/PADI), clivus length $(\mathrm{CL})$, foramen magnum diameter (FMD), Boogard's and basal angle (BOO \& BA) were measured and analyzed.

Statistical Analysis Statistical analysis was done using Microsoft Excel 2016. A webbased, open source application known as OpenEpi.com (version 3.01) was used for applying unpaired $t$-test.

Results This study had a mean age of 42.9 years. The difference in mean value of AADI between male and female population was not found to be statistically significant, while in case of PADI, CL, FMD, BOO and BA, it was found to be significant $(p<0.05)$. On comparison of cases with age $\leq 20$ years and $>20$ years, we found the difference in values of $A D I, C L$ and FMD to be statistically significant $(p<0.05)$.

Conclusion Although there are some similarities, namely, AADI measurements as compared with other studies, there are differences in cutoff values of other parameters. Being a major draining reference center for rural population in India, this data can be extrapolated to a similar population for reference.
\end{abstract}

DoI https://doi.org/

10.1055/s-0040-1712719

ISSN 0976-3147.
C)2020 Association for Helping

Neurosurgical Sick People
License terms

(우 (1) $\ominus \circledast$ 


\section{Introduction}

Craniovertebral junction (CVJ) is the most complex structure of human spine, which harbors and protects vital neural and vascular structures in addition to providing mobility greater than any other spine segment. ${ }^{1}$ Any deformity of this segment subjected to correction is complicated, and detailed knowledge of this area is mandatory prior to any intervention. Majority of literature is focused on techniques to correct the deformity, and there exists paucity regarding the normal anatomy. Most of the normative data published are based on studies conducted by Western authors. With recent advances in fusion techniques for CVJ junction, the knowledge of normal anatomy for specific population cannot be underestimated.

Vidharbha region, where our study was conducted, has a large population suffering from malnourishment. More than half of illiterate females from this region suffer from being underweight and stunted. ${ }^{2}$ Farming and hard labor form the bulk of the occupation here, which they practice from as early as childhood. Apart from the congenital causes for atlantoaxial instability (AAI), protein-calorie malnutrition, deficiency in specific vitamins, and poor delivery practices can play a role in the process of initiation of AAI. ${ }^{3}$ Carrying of heavy load on head for a long time can accelerate spine and CVJ degeneration and put the individual at risk of $\mathrm{AAI}^{3,4}$

The normative data of this rural population can be of utmost importance. This study was aimed at analyzing the data of rural population of central India. Six parameters were studied in detail including anterior atlantodental interval (AADI), posterior atlantodental interval (PADI), clivus length $(\mathrm{CL})$, foramen magnum diameter (FMD), basal angle (BA), and Boogard's angle (BOO).

\section{Materials and Methods}

This was an observational retrospective analysis conducted at the Department of Neurosurgery and Department of Radiology of Mahatma Gandhi Institute of Medical Sciences, Sewagram, from December 2018 to May 2019. Permission from the Institutional Ethical Committee was taken. Since medical ethics does not permit exposure of individual to radiation without clinical symptoms, we conducted this study on patients who came to our department with head injury and were advised imaging for further evaluation. This study includes all the head injury patients who were advised CT brain and cervical spine but reported normal CT cervical spine. Patients having prior history of autoimmune disease, neurological deficit, and any cervical spine pathology on CT cervical spine were not included in the study.

A total of 255 patients were included. CT brain of all the patients was performed in a Wipro-GE multi-slice CT scanner. All images were retrieved from picture archiving and communication system (PACS). Axial sections were obtained at $0.5 \mathrm{~mm}$ slice thickness and analyzed in "bone window" setting. The following measurements were taken with in-built linear callipers by consultant radiologist.

AAI: Horizontal distance from the posterior margin of anterior atlas arch and anterior margin of odontoid process of axis. This measurement was taken in midline sagittal cuts of CT scan (- Fig. 1A). It was similar to Hinck's measurement. ${ }^{5}$

PADI: Horizontal distance from the anterior margin of posterior atlas arch to the posterior margin of odontoid process of axis in midline sagittal section (-Fig. 1B), which is similar to the definition by Boden. ${ }^{6}$

CL: Distance between top of dorsum sella to the basion in midline sagittal section of CT image ( - Fig. 1C).

FMD: Distance between the anterior margin and posterior margin of foramen magnum in a midline sagittal section of CT image (-Fig. 1D).

BOO: Angle between the top of the dorsum sellae, basion, and opisthion ( - Fig. 1E) ${ }^{?}$

Angle formed by intersection of the line joining the nasion with the center of sellar floor and the line joining the anterior

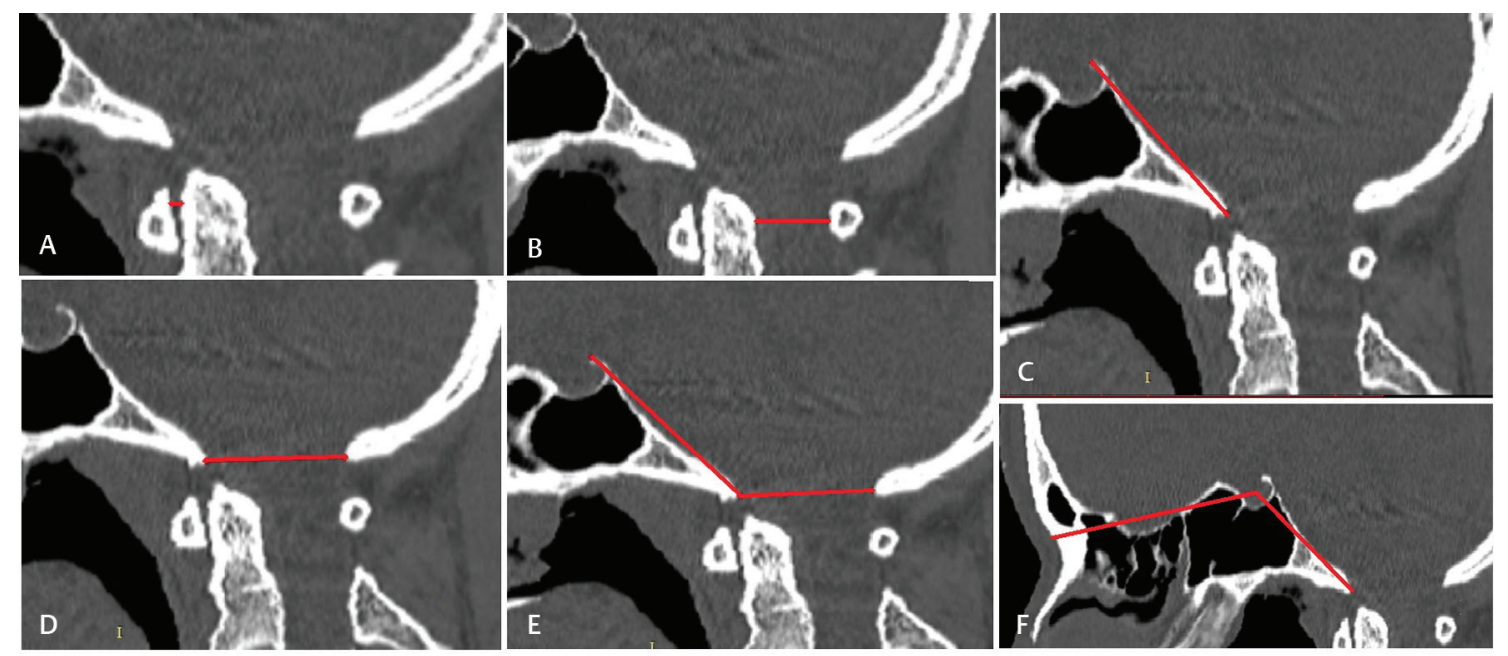

Fig. 1 CT measurements of the following parameters: (A) AADI, (B) PADI, (C) CL, (D) FMD, (E) BOO, (F) BA. AADI, anterior atlantodental interval; $\mathrm{BA}$, basal angle; BOO, Boogard's angle; $\mathrm{CL}$, clivus length; FMD, foramen magnum diameter; PADI, posterior atlantodental interval. 
margin of the foramen magnum with the center of floor of sella ( - Fig. 1F). McGregor $^{8}$ and Poppel et $\mathrm{al}^{9}$ outlined a similar technique.

Statistical analysis was done using Microsoft Excel 2016. A web-based, open source application known as OpenEpi.com (version 3.01$)^{10}$ was used for applying unpaired $t$-test.

\section{Results}

This study consisted of 255 cases, which included 175 male and 80 female patients. The age of the study population varied from 2 to 95 years with mean age of 42.9 years. A total of 225 patients were more than 20 years of age, whereas 30 patients were less than or equal to 20 years of age. - Table 1 shows the mean and standard deviation of various parameters included in the study, while - Table 2 shows comparison of data between male and female. The difference

Table 1 Mean and SD values of various parameters included in this study

\begin{tabular}{|l|l|l|}
\hline & Mean & SD \\
\hline AADI & 1.3 & 0.43 \\
\hline PADI & 16.77 & 2.08 \\
\hline CL & 44.91 & 4.34 \\
\hline FMD & 34.03 & 2.54 \\
\hline BA & 130.24 & 4.4 \\
\hline BOO & 129.14 & 6.35 \\
\hline
\end{tabular}

Abbreviations: AADI, anterior atlantodental interval; BA, basal angle; BOO, Boogard's angle; CL, clivus length; FMD, foramen magnum diameter; PADI, posterior atlantodental interval; SD, standard deviation. in mean value of AADI between male and female was not significant, while in case of PADI, CL, FMD, BA and BOO, it was found to be statistically significant $(p<0.05)$ ( - Table 2 ). On comparison of cases with age $\leq 20$ years and $>20$ years, we found the values of AADI, CL, and FMD to be statistically significant $(p<0.05)$ (-Table 3 ).

There was not a single value of AADI $>2.5 \mathrm{~mm}$ in age group $>20$ years. For age more than 20 years, 214 out of 225 cases (95 percent) reported value of AADI less than $2 \mathrm{~mm}$. While for younger age $\leq 20$ years, 29 out of 30 cases (96 percent) had value of AADI less than $2.6 \mathrm{~mm}$. Based on this observation, we derived the cutoff limit for AADI in age more than 20 years to be $2 \mathrm{~mm}$. For age $\leq 20$ years, the cutoff limit was a little higher and should be considered somewhere around $2.6 \mathrm{~mm}$ (-Table 3 ).

Value of PADI ranged from $12.10 \mathrm{~mm}$ to $26.20 \mathrm{~mm}$ with mean PADI of $16.77 \mathrm{~mm}$ and standard deviation (SD) of 2.08 . A total of 242 out of 255 cases $(\approx 95$ percent) had values of PADI $\geq 13.5 \mathrm{~mm}$. We thus inferred the cutoff value for PADI to be $13.5 \mathrm{~mm}$. Difference between male and female values of PADI was found to be statistically significant.

The mean CL was $44.91 \mathrm{~mm}$ with $\mathrm{SD}$ of $4.34 \mathrm{~mm}$. Difference between CL of male and female was found to be statistically significant.

We found mean BOO as 129.14 degree with SD of 6.35 degree. The variance between male and female values was statistically significant. The upper cutoff limit (mean + 2SD) for BOO in our study was 141.84 degree.

The mean BA in our study was 130.24 degree $(S D=4.4)$.

-Fig. 2 to 7 show the scatter graph for all six parameters against the age of cases. It is evident that the value of AADI decreases as age advances. While CL increases till adolescent

Table 2 Comparison of data between male and female population

\begin{tabular}{|l|l|l|l|}
\hline & Male $(\boldsymbol{n}=\mathbf{1 7 5})$ & Female $(\boldsymbol{n}=\mathbf{8 0})$ & $p$-Value \\
\hline AADI & 1.32 & 1.25 & 0.2279 \\
\hline PADI & 17.03 & 16.2 & 0.0016 \\
\hline CL & 46.13 & 42.24 & $<0.0000001$ \\
\hline FMD & 34.63 & 32.73 & $<0.0000001$ \\
\hline BA & 129.7 & 131.4 & 0.006819 \\
\hline BOO & 128.4 & 130.8 & 0.004955 \\
\hline
\end{tabular}

Abbreviations: $\mathrm{AADI}$, anterior atlantodental interval; BA, basal angle; $\mathrm{BOO}$, Boogard's angle; $\mathrm{CL}$, clivus length; FMD, foramen magnum diameter; PADI, posterior atlantodental interval.

Table 3 Comparison of data based on age distribution

\begin{tabular}{|l|l|l|l|}
\hline & $\begin{array}{l}\text { Age } \leq 20 y \\
\text { Mean } \pm \text { SD } \\
(n=30)\end{array}$ & $\begin{array}{l}\text { Age }>20 y \\
\text { Mean } \pm \text { SD } \\
(\boldsymbol{n}=225)\end{array}$ & $p$-Value \\
\hline AADI & $1.89 \pm 0.456003$ & $1.22 \pm 0.36041$ & $<0.0000001$ \\
\hline PADI & $16.18 \pm 2.068663$ & $16.85 \pm 2.078014$ & 0.1043 \\
\hline CL & $39.85 \pm 5.515604$ & $45.58 \pm 3.676659$ & $<0.0000001$ \\
\hline FMD & $32.71 \pm 3.057262$ & $34.21 \pm 2.413136$ & 0.0143 \\
\hline BA & $131.18 \pm 3.672019$ & $130.12 \pm 4.484117$ & 0.1563 \\
\hline BOO & $131.16 \pm 6.088003$ & $128.87 \pm 6.345031$ & 0.0617 \\
\hline
\end{tabular}

Abbreviations: AADI, anterior atlantodental interval; BA, basal angle; $\mathrm{BOO}$, Boogard's angle; $\mathrm{CL}$, clivus length; FMD, foramen magnum diameter; PADI, posterior atlantodental interval; SD, standard deviation. 


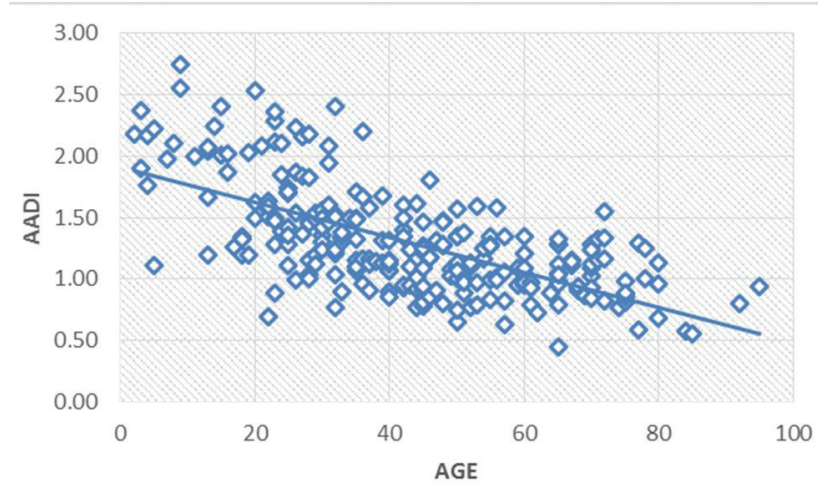

Fig. 2 Scatter diagram illustrating the relationship of AADI with age. Value of AADI decreases as age advances. AADI, anterior atlantodental interval.

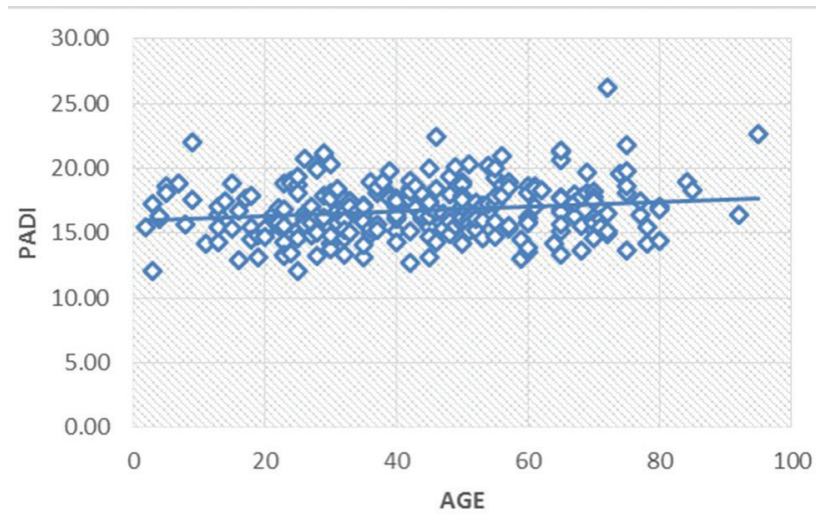

Fig. 3 Scatter diagram illustrating the almost constant relationship of $\mathrm{PADI}$ with age. PADI, posterior atlantodental interval.

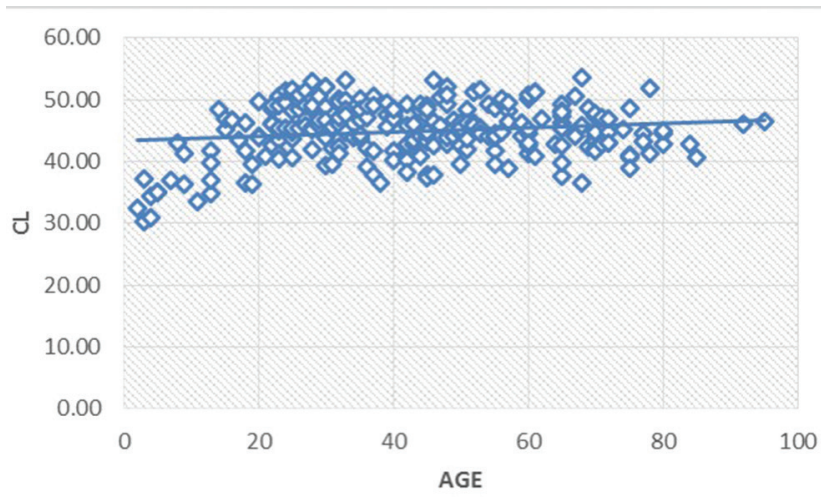

Fig. 4 Scatter diagram illustrating increasing CL till adolescent age followed by a constant plateau thereafter. CL, clivus length.

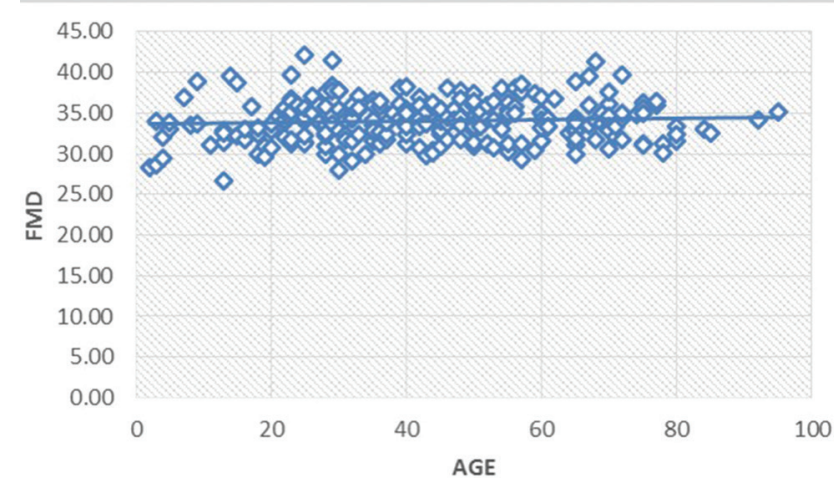

Fig. 5 Scatter diagram illustrating the almost constant relationship of FMD with age. FMD, foramen magnum diameter.

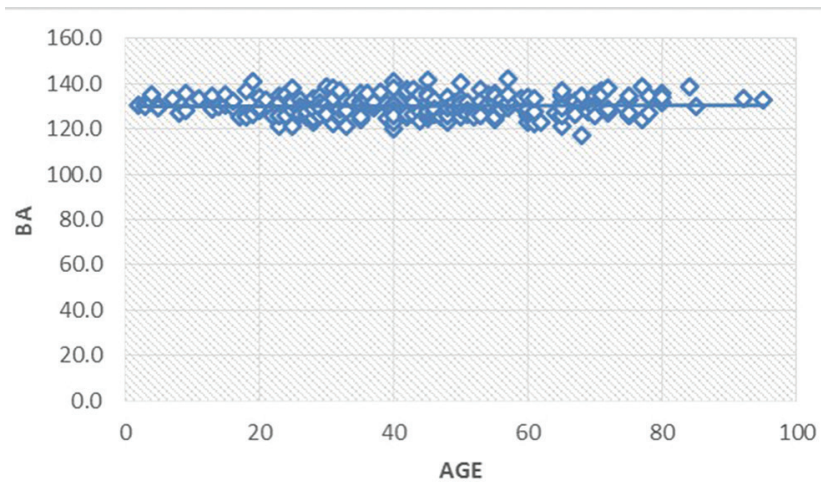

Fig. 6 Scatter diagram illustrating the almost constant relationship of BA with age. $B A$, basal angle.

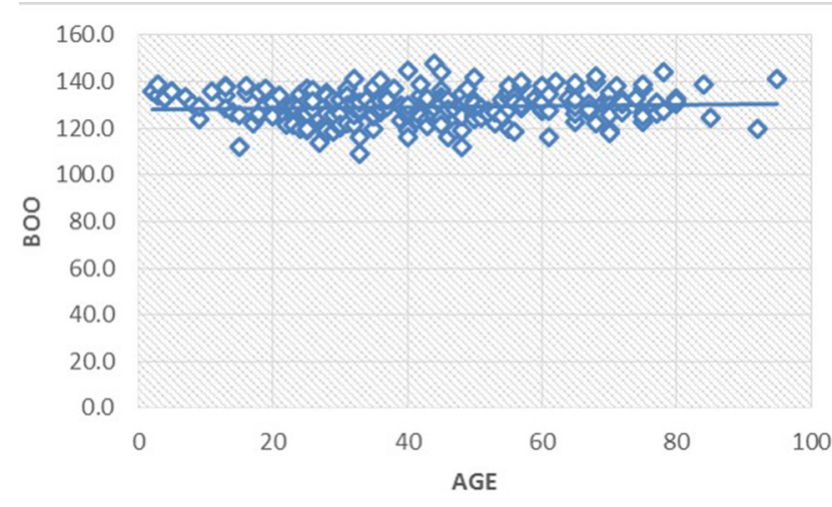

Fig. 7 Scatter diagram illustrating the almost constant relationship of $\mathrm{BOO}$ with age. $\mathrm{BOO}$, Boogard's angle.

Table 4 Comparison of mean BA in various studies based on the techniques used

\begin{tabular}{|l|l|l|l|l|}
\hline Author & Technique & Mean & Maximum & Minimum \\
\hline McGreger $^{8}$ & Radiography & 134 & 148 & 121 \\
\hline Brailsford $^{22}$ & Radiography & 135 & 149 & 121 \\
\hline Poppel et al & Radiography & 137 & 152 & 123 \\
\hline Koenigsberg at al ${ }^{21}$ & MR imaging & 129 & 143 & 113 \\
\hline This study & CT imaging & 130.24 & 142 & 117 \\
\hline
\end{tabular}

Abbreviations: AADI, anterior atlantodental interval; BA, basal angle; BOO, Boogard's angle; $\mathrm{CL}$, clivus length; FMD, foramen magnum diameter; PADI, posterior atlantodental interval. 
age and is constant thereafter, rest of the four parameters are almost constant throughout the age.

\section{Discussion}

The stability of atlantodental space is maintained by many ligaments, namely, atlantodental ligament, transverse ligament of atlas, and alar ligaments. Thus, increase in the ADI is an indirect measurement of instability around the $\mathrm{C} 1-\mathrm{C} 2$ vertebra, although it does not necessarily imply neurological deficit. Most often, increased ADI is due to injury to the transverse ligament of atlas. In our study, we found the mean AADI as $1.3 \mathrm{~mm}$ with $\mathrm{SD}$ of 0.43 which was similar to the findings of Rojas et al ${ }^{11}$ (mean AADI $=1.3 \mathrm{~mm}, \mathrm{SD}=0.37$ ), Kibo Yoon et $\mathrm{al}^{12}$ (mean AADI $=1.4, \mathrm{SD}=0.3$ ) and Dash et $\mathrm{al}^{13}$ (mean $\mathrm{AADI}=1.12, \mathrm{SD}=0.66)$. In review of literature, a Chinese study on 700 patients reported mean AADI of $1.77 \mathrm{~mm}$ with SD of $0.39 \mathrm{~mm} .{ }^{14}$ The discrepancy in the values could be due to the demographic variation. The difference in the male and female values of AADI were statistically insignificant, which is in agreement with other studies. ${ }^{11,14}$

We also found AADI levels to reduce as age advances, which was consistent with findings reported by Liu $\mathrm{K}$ et $\mathrm{al}^{14}$ and Osmotherly $\mathrm{PG}^{15}$ et al. Pediatric age group (less than 18 years) has been reported to have a mean ADI of $2.25 \mathrm{~mm}(\mathrm{SD}=0.24 \mathrm{~mm}),{ }^{16}$ while we have found the mean AADI to be $1.89 \mathrm{~mm}(\mathrm{SD}=0.456 \mathrm{~mm})$ in cases less than 20 years of age ( - Table 3 ).

We conclude that for rural population, the value of AADI $>2.16 \mathrm{~mm}$ (mean +2SD) (-Table 1 ) should be considered as an indirect means of transverse ligament rupture and a setting of limited resources, similar to our institution, should look at the possibility of $\mathrm{C} 1-\mathrm{C} 2$ fixation surgery. Also, for higher values of ADI, one should think of the possibility of higher sagittal angulation of $\mathrm{C} 2$ pedicle screw placement.

Boden et $\mathrm{al}^{6}$ reported that the value of PADI less than $14 \mathrm{~mm}$ was associated with neurological deficits in 97 percent of the cases. This value was significantly greater than our value of PADI. The difference in the value of PADI could be because our study was conducted on multidetector computed tomography (MDCT), while Bodens' study was based on plain. X-ray. Kibo Yoon et $\mathrm{al}^{12}$ on MDCT reported the mean PADI values to be $18 \mathrm{~mm}$ and SD of 2.1 with range between 13.0 to $23.7 \mathrm{~mm}$. In our study, we have found the cutoff limit of PADI associated with significant neural compromise as $13.5 \mathrm{~mm}$. The authors suggest that for cases where PADI is $<13.5 \mathrm{~mm}$ and significant neural compression exists on MRI, decompression of spinal canal in the form of adequate removal of part of $\mathrm{C} 1$ arch should be considered. Also, PADI values in the current paper shows lower values in females, which may predispose them to neuro deficits earlier than men.

$\mathrm{CL}$ value of $44.91 \mathrm{~mm}$ was comparable to the study conducted by Heiss et al (mean $=43.2 \mathrm{~mm}, \mathrm{SD}=3.5 \mathrm{~mm})^{17}$ and Batista et $\mathrm{al}^{18}$ (mean $=44.7 \mathrm{~mm}, \mathrm{SD}=3.5 \mathrm{~mm}$ ). Dufton et a $\mathrm{l}^{19}$ and Heiss et al ${ }^{17}$ have found $\mathrm{CL}$ to be shorter in patients with type I Chiari malformation as compared with normal subjects. Similarly, it was observed that there was a negative correlation between $\mathrm{CL}$ and tonsillar herniation.
The mean FMD was 34.03 with SD of 2.54, which correlates with the study conducted by Batista et $\mathrm{al}^{13}$ (mean $=33.9 \mathrm{~mm}$, $\mathrm{SD}=2.7 \mathrm{~mm}$ ) and Dash et al (mean $=36.29 \mathrm{~mm}, \mathrm{SD}=2.35 \mathrm{~mm}){ }^{18}$

A study conducted by Botelho et al has found an almost similar BOO with mean value of 126 degree (SD $=9.4$ degree) ${ }^{7}$ Alkoc et al also reported the mean value of $\mathrm{BOO}$ as 136.9 degree for the normal control group. ${ }^{20}$ Based on our study, we conclude that diagnosis of platybasia should be made if BOO is > 141.84 degree.

Botelho et al, ${ }^{7}$ Dash ${ }^{13}$ et al, and Konigsberg et a ${ }^{21}$ reported mean values of BA as $119,121.65$, and 129 degrees, respectively. Bothelo ${ }^{7}$ and Dash $^{13}$ measured BA as angle formed by the line between the nasion to dorsum sellae, intersecting the line from the basion to the dorsum sellae. In our study, we measured the BA along the center of pituitary fossa. McGregor, ${ }^{8}$ Poppel, ${ }^{9}$ Konigsberg, ${ }^{21}$ and Brailsford ${ }^{22}$ also evaluated BA similarly in their studies ( - Table 4 ). Botelho et $\mathrm{al}^{7}$ reported that the diagnosis of platybasia should be made when $\mathrm{BA}$ is above 133 degrees. Smoker et $\mathrm{al}^{23}$ advocated that BA must be $<140^{\circ}$ and diagnosis of platybasia should be made for angles above $140^{\circ}$. In our study, we found the upper cutoff limit of BA for male to be 138 ( mean $=129.7, S D=4.139$ ) and female to be $140.9($ mean $=131.4, S D=4.774)$.

Although there have been differences reported in gender-based values of ADI, FMD and BA, they have not been found to be statistically significant, ${ }^{13}$ unlike our findings. We found smaller PADI, FMD, and BA in females as compared with males.

\section{Conclusion}

There are variations in the normative data about CVJ parameters all around the world. Females have lower FMD, lower PADI, and higher values for platybasia angle than men. Since, our center represents a major draining tertiary rural setup in central India, these study interpretations could be extrapolated to the rest of surrounding population of India for future references.

\section{Funding}

None.

\section{Conflict of Interest}

None declared.

\section{References}

1 Goel A. Craniovertebral junction instability: a review of facts about facets. Asian Spine J 2015;9(4):636-644

2 International Institute for Population Sciences (IIPS) and Macro International. National Family Health Survey (NFHS-3), 2005-06: India: Volume I. Mumbai: IIPS; 2007

3 Goel A. Instability and basilar invagination. J Craniovertebr Junction Spine 2012;3(1):1-2

4 Albright AL, Pollack IF, Adelson PD. Principles and Practice of Pediatric Neurosurgery. 2nd ed. New York: Thieme; 2008 $396 \mathrm{p}$

5 Hinck VC, Hopkins CE. Measurement of the atlanto-dental interval in the adult. Am J Roentgenol Radium Ther Nucl Med 1960;84:945-951 
6 Boden SD, Dodge LD, Bohlman HH, Rechtine GR. Rheumatoid arthritis of the cervical spine. A long-term analysis with predictors of paralysis and recovery. J Bone Joint Surg Am 1993;75(9):1282-1297

7 Botelho RV, Ferreira ED. Angular craniometry in craniocervical junction malformation. Neurosurg Rev 2013;36(4):603-610, discussion 610

8 McGreger M. The significance of certain measurements of the skull in the diagnosis of basilar impression. Br J Radiol 1948;21(244):171-181

9 Poppel MH, Jacobson HG, Duff BK, Gottlieb C. Basilar impression and platybasia in Paget's disease. Radiology 1953;61(4):639-644

10 DeanAG, SullivanKM, SoeMM. OpenEpi: Open Source Epidemiologic Statistics for Public Health. Available at: www. OpenEpi.com. Accessed February 1, 2020

11 Rojas CA, Bertozzi JC, Martinez CR, Whitlow J. Reassessment of the craniocervical junction: normal values on CT. AJNR Am J Neuroradiol 2007;28(9):1819-1823

12 Yoon K, Cha S, Ryu J, Park D, Lee S, Joo K. Anterior atlantodental and posterior atlantodental intervals on plain radiography, multidetector CT, and MRI. J Korean Soc Radiol 2015;72(1):57-64

13 Dash C, Singla R, Agarwal M, et al. Craniovertebral junction evaluation by computed tomography in asymptomatic individuals in the Indian population. Neurol India 2018;66(3):797-803

14 Liu K, Xie F, Wang D, et al. Reference ranges for atlantodental interval in adults and its variation with age and gender in a large series of subjects on multidetector computed tomography. Acta Radiol 2015;56(4):465-470
15 Osmotherly PG, Farrell SF, Digby SD, Rowe LJ, Buxton AJ. The influence of age, sex, and posture on the measurement of atlantodental interval in a normal population. J Manipulative Physiol Ther 2013;36(4):226-231

16 Vachhrajani S, Sen AN, Satyan K, Kulkarni AV, Birchansky SB, Jea A. Estimation of normal computed tomography measurements for the upper cervical spine in the pediatric age group. J Neurosurg Pediatr 2014;14(4):425-433

17 Heiss JD, Suffredini G, Bakhtian KD, Sarntinoranont M, Oldfield EH. Normalization of hindbrain morphology after decompression of Chiari malformation Type I. J Neurosurg 2012;117(5):942-946

18 Batista UC, Joaquim AF, Fernandes YB, Mathias RN, Ghizoni E, Tedeschi H. Computed tomography evaluation of the normal craniocervical junction craniometry in 100 asymptomatic patients. Neurosurg Focus 2015;38(4):E5

19 Dufton JA, Habeeb SY, Heran MK, Mikulis DJ, Islam O. Posterior fossa measurements in patients with and without Chiari I malformation. Can J Neurol Sci 2011;38(3):452-455

20 Alkoç OA, Songur A, Eser O, et al. Stereological and morphometric analysis of MRI Chiari malformation type-1. J Korean Neurosurg Soc 2015;58(5):454-461

21 Koenigsberg RA, Vakil N, Hong TA, et al. Evaluation of platybasia with MR imaging. AJNR Am J Neuroradiol 2005;26(1):89-92

22 Brailsford JF, The Radiology of Bones and Joints. London: J\&A Churchill; 1994:257-324

23 Smoker WR. Craniovertebral junction: normal anatomy, craniometry, and congenital anomalies. Radiographics $1994 ; 14(2): 255-277$ 